\title{
Carbohydrate-based Trojan microparticles as carriers for pulmonary delivery of lipid nanocapsules using dry powder inhalation
}

Anita Umerska ${ }^{1,2}$, Naila A. Mugheirbi ${ }^{1}$, Agnieszka Kasprzak ${ }^{1}$, Patrick Saulnier ${ }^{2}$, Lidia Tajber ${ }^{1,3,}{ }^{*}$

1) School of Pharmacy and Pharmaceutical Sciences, Trinity College Dublin, Dublin 2, Ireland

2) MINT, UNIV Angers, INSERM 1066, CNRS 6021, Université Bretagne Loire, Angers, Cedex, France

3) Synthesis and Solid State Pharmaceutical Centre, Ireland

* corresponding author: Lidia Tajber, School of Pharmacy and Pharmaceutical Sciences, Trinity College Dublin, College Green, Dublin 2, Ireland. Tel: +35318962787. Email: Itajber@tcd.ie

\begin{abstract}
This study proposes lipid nanocapsules (LNCS)-based Trojan particles made by entrapping $59 \pm 3 \mathrm{~nm}$ LNCs in carbohydrate-based microparticles via spray drying. This work focused on optimisation of maintenance of the nanocarrier colloidal properties, solid state properties and suitability of Trojan particles for pulmonary deposition. The properties of Trojan particles were evaluated as a function of the nature of carbohydrate, the feed concentration and LNC loading. The presence of nanocapsules had a significant impact on the size and morphology of microparticles and their solid state properties. Spray drying did not destroy the LNCs and their size after reconstitution varied between $78 \pm 1$ and $121 \pm 1 \mathrm{~nm}$. The lactose, trehalose and raffinose-based Trojan particles were readily dispersed as aerosols with mass median aerodynamic diameters between $5.3 \pm 0.1$ and $6.2 \pm 0.1 \mu \mathrm{m}$ using a dry powder inhaler. In conclusion, LNC-Trojan particles were shown to successfully not only to encapsulate the lipid nanocapsules but also to release them.
\end{abstract}

Keywords: Trojan particle, spray drying, microparticles, pulmonary nanoparticles, lipid nanoparticles, carbohydrate. 


\section{Introduction}

Pulmonary route has been considered for local and systemic delivery of numerous active pharmaceutical ingredients including biomolecules. The advantages of local delivery to lungs include higher drug doses at the site of action and reduced systemic side effects. The benefits of using pulmonary route for systemic drug delivery include large surface area available for absorption (approximately $100 \mathrm{~m}^{2}$ ), the very thin pulmonary barrier (the distance between the air in the alveolar lumen and the capillary blood flow is less than $400 \mathrm{~nm}$ ) and the elevated blood flow (5 L/min), relatively low metabolic activity and efflux transporter activity compared to oral route, avoidance of first pass effect [1-5]. Recently, there is an interest in the use of nanocarriers as drug delivery systems due to their small size and large surface area [6]. A lot of components of living cells, such as ribosomes, membrane transporters, receptors and cell signalling systems are constructed at the nano-level. The nanocarriers fall in the same size range as these biological entities, therefore they can readily interact with the molecules within the cell and on cell surface [2]. Nanoparticles (NPs) protect sensitive substances or bioactive molecules and may provide their controlled release [7-11]. Another important advantage of NPs is their ability to effectively deliver therapeutic agent over a long period of time without degradation occurring before it reaches the cellular target [6]. Hence, nanoencapsulation can increase the therapeutic efficacy of drugs, their specificity and targeting ability [12]. Moreover, nanoparticulate carriers have a greater chance to escape from the clearance mechanisms by the lung defence systems compared with microparticulate carriers [2]. NPs fabricated using natural biomolecules such as lipids are expected to be an appropriate choice for clinical applications [13]. Among them, lipid nanocapsules (LNCs) are biomimetic nanocarriers that offer numerous advantages such as feasibility at laboratory or large scale, manufacturability via an organic solvent-free, low energy method, good physical stability, biocompatibility, possibility of surface modification [14-18]. Although initially they were considered as carriers for lipophilic drugs [14,19], recent studies revealed their potential as carriers for water soluble molecules such as peptides $[17,20]$.

Inhaled drug delivery devices include nebulizers, dry powder inhalers and pressurised metered-dose inhalers [3]. Previous studies were performed on nebulization of the LNCs [15, 19]. Nevertheless, nebulization has some inconveniences such as low efficiency, time-consuming administration, poor reproducibility and great variability [3]. On the other hand, dry powder inhalers are preferred because of their stability and processing (they are typically formulated as solid state blends of components). In contrast to metered-dose inhalers, dry powder inhalers do not contain propellants and thus are environmentally friendly [3]. 
Despite the numerous advantages, the use of drug-loaded NPs themselves for pulmonary applications is limited because their mass median aerodynamic diameter (MMAD) is not suitable for inhalation purposes and they can be exhaled after inspiration. Considering the effects of aerodynamic size on regional lung deposition patterns, particles with MMAD between 1 and $5 \mu \mathrm{m}$ are desirable to facilitate predominant deposition in the smaller airways [21]. The fine particle fraction (FPF) represents the mass percentage of drug particles with an aerodynamic diameter below $5 \mu \mathrm{m}$ and is used for in vitro assessment of the aerodynamic properties of aerosols [22]. Current dry powder inhalers on the market have FPFs ranging between 10 and 70\% [23]. Moreover, small size of NPs can lead to particle aggregation due to high surface energy thereby making handling of the NPs in dry powder form very difficult $[2,24,25]$. Therefore, the major challenge for pulmonary delivery of NPs is to find a proper carrier system with an MMAD suitable for pulmonary delivery $[2,26]$. A potential solution to this problem is using a Trojan horse strategy, i.e. incorporation of nanoparticles into larger carriers with suitable aerodynamic properties. Spray drying is convenient because it enables transforming of aqueous dispersions of the nanocarriers into a dry powder with an aerodynamic diameter suitable for pulmonary deposition which can be stored for a very long period. Moreover, the conversion of aqueous dispersion of lipid nanocarriers to dry powder can improve their stability, lower storage and transport costs and facilitate their use [27, 28].

Carbohydrates such as lactose and mannitol are widely used as excipients for dry powder inhalers because they are approved by the FDA (Food and Drug Administration) and other regulatory bodies for pulmonary delivery. One of their advantages is the lack of toxicity [1]. Trehalose is widely used in pharmaceutical formulations as a lyoprotectant because it shows low tendency to crystallise and relatively high glass transition temperature $(\operatorname{Tg})[11,25,29]$. Moreover, non-reducing carbohydrates such as raffinose and trehalose have properties that make them promising excipients for the protection of biomolecules, such as peptides or proteins [30], that could potentially be loaded into the LNCs. Carbohydrates have the advantage of availability at low costs, low viscosity in concentrated solutions and ability to produce a good glass upon spray drying [31]. Trehalose, raffinose and sucrose are non-reducing carbohydrates and as such they have the advantage that they will not undergo the Maillard browning reaction [4].

Trojan particles differ from conventional spray dried particles in that the former comprise NPs that are entrapped in the microparticles. To date Trojan particles encapsulating PLGA, polystyrene, silica NPs, liposomes and NPs made of pure drug or nanoemulsions have been proposed [24, 32-38]. The nanocarriers were entrapped within the microparticles composed of hyaluronic acid and phospholipid (DPPC) [32], lactose and phospholipids (DPPC, DPME) [24], mannitol, lactose, or $\alpha$-cyclodextrin [35] or 
gum arabic, whey protein, polyvinyl alcohol, modified starches, maltodextrin, hydroxypropyl- $\beta$ cyclodextrins and pregelatinized hydroxypropyl pea starch [34], maltodextrin combined with a surface active biopolymer or a small molecule surfactant [39]. The major problem concerning encapsulation of nanocarriers within the Trojan particles is the conservation of the nanocarriers structure and size distribution during spray drying process [34]. Spray drying of nanocarriers, particularly lipidic, is very challenging. There have been attempts to prepare the spray dried and spray freeze dried LNCs by Ali et al., [35], but they were unsuccessful. This group tried to prepare LNCs in the dry form using trehalose as a carrier. Spray drying proved to be unsuccessful because only a waxy mass was obtained as product. Spray freeze drying yielded microparticles with a very low fine particle fraction (2\%) and an MMAD of $14.2 \pm 2.6 \mu \mathrm{m}$, hence this product is not suitable for pulmonary application [35]. Therefore, in the current study we attempted to modify formulation parameters such as the choice of carbohydrate material (raffinose, trehalose, sucrose, lactose or mannitol), feed concentration and LNC loading to decrease the MMAD and increase the FPF. Three important parameters were considered: satisfactory maintenance of the nanocarrier colloidal properties, solid state properties and finally in vitro suitability of Trojan particles for pulmonary deposition.

\section{Materials and methods}

\subsection{Materials}

Labrafac $^{\circledR}$ WL1349 (caprylic/capric acid triglycerides-C8/C10-TG) was kindly provided by Gattefossé S.A. (France). Lipoid ${ }^{\circledR}$ S75-3 (hydrogenated lecithin) and Kolliphor ${ }^{\circledR}$ HS 15 (Solutol ${ }^{\circledR}$ HS15, macrogol 15 hydroxystearate, polyoxyl 15 hydroxystearate; molecular weight $963.24 \mathrm{~g} / \mathrm{mol}$ ) were kindly supplied by Lipoid Gmbh (Germany) and BASF (Germany), respectively. Sunset yellow, D-mannitol, sucrose, lactose (as monohydrate), trehalose (as dihydrate) and raffinose (as pentahydrate) were obtained from Sigma Aldrich (Ireland). All other chemicals and solvents were of analytical grade.

\subsection{Preparation of LNCs}

LNCs composed of polyoxyl 15 hydroxystearate (MHS) (43.41\%), hydrogenated lecithin (3.85\%) and caprylic/capric acid triglycerides (TGs) (52.74\%) were prepared at a concentration of $177 \mathrm{mg} / \mathrm{ml}$ using the phase inversion process described elsewhere [19]. Briefly, the above-mentioned LNC components (768 mg, $68 \mathrm{mg}$, and $933 \mathrm{mg}$, respectively) and $\mathrm{NaCl}(89 \mathrm{mg}$ ) were weighed and mixed with $3 \mathrm{ml}$ of water. The sample was then heated to $95^{\circ} \mathrm{C}$ and cooled to $60{ }^{\circ} \mathrm{C}$. The sample was treated with three heating-cooling cycles and during the last cooling, at $82^{\circ} \mathrm{C}$ (phase inversion temperature) the system was diluted with cold $\left(\sim 4^{\circ} \mathrm{C}\right)$ water to a final volume of $10 \mathrm{ml}$.

\subsection{Preparation of LNCs-carbohydrate aqueous mixtures}


Carbohydrate (mannitol, sucrose, lactose monohydrate, trehalose dihydrate, raffinose pentahydrate) was dissolved in water. This aqueous solution was then mixed with the LNC dispersion to obtain the desired carbohydrate/LNCs mass mixing ratio (MMR). The samples were diluted with water to achieve a final carbohydrate concentration of $0.5 \%, 1 \%, 5 \%$, and $10 \%(\mathrm{w} / \mathrm{v})$.

\subsection{Spray drying of LNCs-carbohydrate mixtures to prepare Trojan microparticles}

Trojan microparticles were prepared by spray-drying of carbohydrate-LNCs aqueous mixtures using a Büchi Mini Spray Dryer B-290 (Büchi, Switzerland) operating in the open cycle mode configuration as described elsewhere [40] with a two-fluid nozzle. The carbohydrate concentrations used were $0.5 \%$, $1 \%, 5 \%$ and $10 \%(\mathrm{w} / \mathrm{v})$ and the carbohydrate/LNCs MMR was 25 . In the case of $1 \%(\mathrm{w} / \mathrm{v})$ raffinose the following MMRs were tested: $0.4,0.8,1.6,3.1,6.3,12.5,25,50$ and 100. The inlet temperature was set at $140{ }^{\circ} \mathrm{C}$, and the feeding pump rate was adjusted to $15 \%$ (flow of $5.4 \mathrm{ml} / \mathrm{min}$ ). Nitrogen was used as the drying gas (flow of $504 \mathrm{~L} / \mathrm{min}$, aspirator rate of $80 \%$ ). These settings yielded the outlet temperature of approximately $66^{\circ} \mathrm{C}$. A high-efficiency cyclone separator was employed for collection of the spray dried product.

\subsection{Characterisation of size and size distribution of LNCs}

Sample viscosity was measured using a low-frequency vibration viscometer (SV-10 Vibro Viscometer, A\&D Company, Ltd.). The z-average particle diameter and the polydispersity indexes of the LNCs were determined by Dynamic Light Scattering (DLS). LNCs were diluted with water to obtain a concentration of $3 \mathrm{mg} / \mathrm{ml}$. Spray-dried LNCs were redispersed in water to obtain an LNC concentration of $3 \mathrm{mg} / \mathrm{ml}$. DLS measurements were carried out on a Zetasizer nano series Nano-ZS fitted with a $633 \mathrm{~nm}$ laser (Malvern Instruments, UK) and with the scatter angle fixed at $173^{\circ}$. Each analysis was carried out at $25^{\circ} \mathrm{C}$ in triplicate. The results obtained were corrected for sample viscosity.

\subsection{Characterization of size and size distribution of Trojan microparticles}

The size and size distribution of Trojan microparticles was determined using a Mastersizer 2000 laser diffraction instrument (Malvern Instruments, UK). Dry powders were dispersed using Scirocco 2000 feeder attachment. The pressure was set at 2 bar and a vibration feed rate of $50 \%$ was used in order to achieve an obscuration within the limits of $0.5 \%-6 \%$. Samples were run in triplicate. Mastersizer 2000 software was used for data evaluation $[4,30]$. Standard percentile reading $d(0.5), d(0.1)$ and $d(0.9)$ were obtained from the analysis. $D(0.5)$, the median particle diameter or the median of the volume distribution, is the size in micrometres at which $50 \%$ of the sample is smaller and $50 \%$ is larger. $D(0.1)$ is the size of particle below which $10 \%$ of the sample lies, whereas $d(0.9)$ is the size of particle 
below which $90 \%$ of the sample lies. The span, i.e. the measurement of the width of distribution, was calculated as:

$$
\operatorname{Span}=\frac{(d(0.9)-d(0.1))}{d(0.5)} \quad(\text { Eqn.1) }
$$

\subsection{Morphology of Trojan microparticles}

A Zeiss Supra variable Pressure Field Emission Scanning Electron Microscope (Germany) equipped with a secondary electron detector and an accelerating voltage of $5 \mathrm{kV}$ was used for the morphological examination of Trojan particles. Powders were placed on carbon tabs fitted on aluminium stubs. They were sputter coated with gold/palladium under vacuum before analysis as described by Mugheirbi et al., [40].

\subsection{Differential Scanning Calorimetry}

DSC experiments were performed using a Mettler Toledo DSC 821e with a refrigerated cooling system LabPlant RP-100. Nitrogen was used as the purge gas. Aluminium sample holders were sealed with a lid and pierced to provide three vent holes. Accurately weighed samples (7-9 mg) were placed in aluminium pans. Measurements were carried out at a heating rate of $10{ }^{\circ} \mathrm{C} / \mathrm{min}$ applying the temperature range $25-250^{\circ} \mathrm{C}$. The unit was calibrated with indium and zinc standards. The DSC system was controlled by Mettler Toledo STARe software (version 6.10) [7, 40].

\subsection{Powder X-ray diffraction (PXRD)}

PXRD measurements were performed using a Rigaku Miniflex II, desktop X-ray diffractometer (Japan) equipped with a $\mathrm{Cu}$ K $\alpha$ radiation X-ray source with a Haskris cooling unit. The tube output voltage used was $30 \mathrm{kV}$ and tube output current was $15 \mathrm{~mA}$. A Cu-tube with $\mathrm{Ni}$-filter suppressing $\mathrm{K} \beta$ radiation was used. Measurements were taken from 5 to 40 on the 2 theta scale at a step size of $0.05^{\circ}$ per second [7].

\subsection{In vitro aerosol deposition studies using Next Generation Impactor (NGI)}

Samples were spray dried with the addition of sunset yellow dye ( $5 \mathrm{mg}$ of dye/g of powder). A total of $20 \pm 2 \mathrm{mg}$ of powder was loaded into a hard gelatin capsule (size 3). A dry powder inhalation device (Cyclohaler ${ }^{\circledR}$, N.V. Medicopharma, Zaandam, Netherlands) [41] was connected to the mouthpiece of a Next Generation Impactor (Copley Scientific Limited, UK). The capsule containing the inhaled powder was placed in the holder of the inhaler device, punctured, and a vacuum pump was used to produce the air stream of $60 \mathrm{~L} / \mathrm{min}$ for $4 \mathrm{~s}$ [42]. The powder that remained in the capsule and the powder that was deposited in the device, mouthpiece, in stages (S) 1-7 (corresponding to the following cut off 
diameters: S1: $8.06 \mu \mathrm{m}$, S2: $4.46 \mu \mathrm{m}, \mathrm{S3}: 2.82 \mu \mathrm{m}, \mathrm{S} 4: 1.66 \mu \mathrm{m}, \mathrm{S} 5: 0.94 \mu \mathrm{m}, \mathrm{S6}: 0.55 \mu \mathrm{m}, \mathrm{S} 7: 0.36 \mu \mathrm{m})$, and filter was collected and dissolved in water. The content of sunset yellow was then quantified by measuring the absorbance at $480 \mathrm{~nm}$ using a UV-1700 PharmaSpec UV visible spectrophotometer (Shimadzu, Japan). Standard solutions of sunset yellow were prepared by dissolving accurately weighed spray dried powders in deionized water. The method showed good linearity $\left(R^{2}=0.999\right)$. The quantification and detection limits were $0.2 \mu \mathrm{g}$ and $0.1 \mu \mathrm{g}$ of sunset yellow per $\mathrm{ml}$, respectively. Each test was repeated three times. The fine particle fraction (FPF) (i.e. the total amount of particles with aerodynamic diameters smaller than $5.0 \mu \mathrm{m}$ ) was calculated by interpolation from the inverse of the standard normal cumulative mass distribution less than stated size cut-off against the natural logarithm of the cut-off diameter of the respective stages. The FPF, considered as the respirable fraction, was expressed as a percentage of the total recovered dose. The mass median aerodynamic diameter (MMAD) of the particles and the geometric standard deviation (GSD) were determined using a web-based application, MMAD calculator (http://www.mmadcalculator.com/).

\subsection{Statistical analysis}

Results are shown as mean \pm standard deviation from three independent experiments. The statistical significance of the differences between samples was determined using either one-way analysis of variance (ANOVA) or two-way ANOVA. Differences were considered significant at $p<0.05$.

\section{Results}

\subsection{Preparation and characterisation of LNCS}

The size of the LNCs is in the low nanometric scale, typically between 20-100 nm. Among the LNCs, the nanocarriers with a size 50-60 nm have been the most widely studied thus far $[10,15,16]$, hence they were selected for this work. In this work, LNCs composed of MHS (43.41\%), hydrogenated lecithin (3.85\%) and TGs (52.74\%) were successfully prepared with a diameter of $59 \pm 3 \mathrm{~nm}$ and polydispersity index of $0.041 \pm 0.015$, consistent with previous reports $[10,15,18,19]$. These LNCs have a complex core-shell structure that upon any further processing must be retained. The core, composed of medium chain triglycerides, is surrounded by the shell containing a PEGylated surfactant and, optionally, other cosurfactants such as lecithin $[10,18]$. Although the LNCs show a slightly negative zeta potential, they remain stable when stored as an aqueous dispersion because of steric stabilization due to the presence of PEG moieties (MHS) on the surface of the nanocarriers [18].

We made attempts to obtain the LNCs on their own in the powder form using spray drying, but it was impossible to recover LNCs in the collection vessel because the semi-solid product was deposited on the walls of the drying cylinder and the cyclone. Therefore, a small sample of LNC dispersion was dried 
in a vacuum oven for $48 \mathrm{~h}$ at room temperature and analysed by DSC and PXRD. The DSC analysis of LNCs revealed four melting endotherms (Figure 1a). The first melting endotherm with an onset at $14.6^{\circ} \mathrm{C}(\Delta \mathrm{H}=37.55 \mathrm{~J} / \mathrm{g})$ can be ascribed to TGs [43], the component of the oil core of the LNCs. The next two endotherms (onset at $2.6^{\circ} \mathrm{C}, \Delta \mathrm{H}=21.05 \mathrm{~J} / \mathrm{g}$ and onset at $27.3^{\circ} \mathrm{C}, \Delta \mathrm{H}=4.0 \mathrm{~J} / \mathrm{g}$ ) can be ascribed to MHS [43]. The presence of two MHS melting endotherms may be explained by the fact that this surfactant is composed of polyglycol mono- and di-esters of 12-hydroxystearic acid (approximately $70 \%$ ) and free polyethylene glycol (approximately 30\%) [18, 19]. The last melting endotherm with an onset at $71.2^{\circ} \mathrm{C},(\Delta \mathrm{H}=0.7 \mathrm{~J} / \mathrm{g})$ can be ascribed to hydrogenated lecithin [43]. One amorphous halo, centred at around $20^{\circ} 2 \theta$, was visible in PXRD diffractogram of LNCs (Figure 1b), thereby indicating that the LNCs were PXRD amorphous. The Bragg peak at $31.8^{\circ} 2 \theta$ can be ascribed to sodium chloride [7] as the LNCs were dispersed in aqueous $\mathrm{NaCl}$ solution.

\subsection{Mannitol-based Trojan particles}

Both, mannitol feed concentration and the presence of LNCs exerted a significant effect on the median diameter of Trojan particles ( $p=0.0195$ and $p<0.0001$, respectively) and the interaction between these parameters was significant $(p<0.0001)$ (Figure $2 a)$. The width of size distribution (Span) was affected by the LNC presence $(p=0.0004)$, but not by mannitol concentration in feed $(p>0.05)$. Spray drying of an aqueous solution of mannitol yielded small particles, with the median particle size varying between $2.975 \pm 0.01 \mu \mathrm{m}$ (mannitol feed concentration $0.5 \% \mathrm{w} / \mathrm{v}$ ) and $5.69 \pm 0.34 \mu \mathrm{m}$ (mannitol feed concentration $10 \% \mathrm{w} / \mathrm{v})$. Scanning electron micrographs of spray dried mannitol displayed hollow spherical particles with rough surfaces containing mannitol crystals (Figure 3a). Another important characteristic of these particles was the presence of holes, cracks and an orifice in the mannitol particle shells, probably due to evaporation of the vapour that escaped from the inner of the droplets through the solid crust already formed in the course of the drying process on the surface of the droplet [44].

Interestingly, the incorporation of the LNCS resulted in a drastic increase in particle size (median particle sizes varied between $11.09 \pm 0.14 \mu \mathrm{m}$ and $12.57 \pm 1.145 \mu \mathrm{m}$ ) and the presence of aggregates (Figure 2a). The LNC-mannitol Trojan particles fused and formed aggregates and they did not show spherical shapes. The presence of crystalline-like formations was also observed (Figure 3b). The formation of crystalline mannitol after spray drying in both, mannitol and mannitol/LNCs, samples was confirmed by DSC and PXRD (Figure $2 \mathrm{~b}$ and $\mathrm{c}$ ). The DSC curves of mannitol spray dried without LNCs showed only one sharp melting peak with an onset at $165^{\circ} \mathrm{C}$, similar to the starting material (Figure 2b). Mannitol is a polymorphic pharmaceutical excipient, which commonly exists in three forms: alpha (melting point of $165.3^{\circ} \mathrm{C} / 166^{\circ} \mathrm{C}$ ), beta (melting point of $166.7^{\circ} \mathrm{C} / 166.5^{\circ} \mathrm{C}$ ) and delta (meting point 
incongruent, either $146.8-156.2^{\circ} \mathrm{C}$ or $\left.150-158^{\circ} \mathrm{C}\right)[45,46]$. Thus, DSC indicated the presence of either the form alpha or beta, but they are not distinguishable by this technique due to the similarity of their melting points. The PXRD data revealed that the starting material was the beta polymorph of mannitol (Figure 2c). Spray drying of mannitol without the presence of LNCs yielded the beta form as well. DSC of the spray dried mixture of mannitol/LNCs showed that the melting point of this sample was 164$165^{\circ} \mathrm{C}$. PXRD showed that spray drying of mannitol/LNCs mixtures yielded the alpha polymorph of mannitol (Figure 2c). A polymorphic transition of mannitol was observed when co-processing with itraconazole NPs [36]. Possible consequences of such a transformation could be altered storage shelflife, flowability and aerodynamic properties.

Due to the presence of agglomerates and particle morphology deviating from the spherical shape, aerodynamic diameter measurements were not performed for mannitol/LNCs mixtures, as the main criteria for selecting favourable systems for NGI studies were small geometric sizes of Trojan particles, adequate LNC reconstitution and generally spherical shapes of the spray dried particles. Despite the Trojan particle aggregation, LNCs were successfully reconstituted from the spray dried powders, without the formation of macroscopic aggregates visible to the naked eye. The diameter of redispersed LNCs, varying from $103 \pm 1 \mathrm{~nm}$ (mannitol $10 \%$, LNCs $0.4 \%, M M R=25$ ) to $106 \pm 1 \mathrm{~nm}$ (mannitol $0.5 \%$, LNCs $0.02 \%, \mathrm{MMR}=25$ ) was significantly affected by processing with the carbohydrate $(p<0.0001)$, so was the polydispersity index (Figure $2 d)$. However, neither the size nor the polydispersity index of the reconstituted nanocapsules was influenced by the feed concentration $(p>0.05)$.

\subsection{Sucrose-based Trojan particles}

Sucrose starting material was crystalline as shown by DSC and PXRD (Figure 4a and b). It exhibited a melting point with an onset at $182.6{ }^{\circ} \mathrm{C}$ (Figure 4a). Sucrose is believed to exist in the monoclinic hemihedral form, which melts and decomposes around $185^{\circ} \mathrm{C}$ to $190^{\circ} \mathrm{C}[40]$. Another endothermic event with an onset at $150.3{ }^{\circ} \mathrm{C}$ could be attributed to the presence of a low melting metastable polymorph in which the inter-residue intramolecular hydrogen bonds between the hydroxyl groups and the glucopyranose ring oxygen were misaligned [47]. Spray drying of sucrose from its aqueous solution was not successful because the yield was approximately $5 \%$ and most of the product remained in the drying chamber or in the cyclone. This behaviour may be explained by the fact that the $\mathrm{Tg}$ of sucrose $\left(46-74^{\circ} \mathrm{C}\right)$ [48] was close to the outlet temperature. No particle size analysis of this residue was possible, but SE micrographs revealed the presence of fused mass with smooth surfaces (Figure 3c). Spray dried sucrose was PXRD amorphous (Figure 4b). In the DSC scan, a Tg with the midpoint at $47.6^{\circ} \mathrm{C}$ was followed by an exothermic event, most likely crystallisation, with a peak at 
$85.9^{\circ} \mathrm{C}$ and two endothermic events with peaks located at $152.5^{\circ} \mathrm{C}$ and $186.5{ }^{\circ} \mathrm{C}$, similar to those observed for starting material.

Interestingly, when sucrose was spray-dried with the LNCs (MMR $=25)$ the yield was markedly increased. The median diameter of the sucrose-LNC Trojan particles was significantly affected by the feed concentration $(p<0.0001)$, similarly to Span $(p=0.0096)$ (Figure $4 c)$. The smallest particles $(d(0.5)=9.62 \pm 0.04 \mu \mathrm{m})$ were obtained at the lowest carbohydrate concentration (sucrose $0.5 \%$, LNCs $0.02 \%)$. The largest particles $(\mathrm{d}(0.5)=23.29 \pm 1.48 \mu \mathrm{m})$ were formed when spray dried at a concentration of $1 \%$ of sucrose (LNCs $0.04 \%$ ), and the $d(0.5)$ value decreased again to $16.35 \pm 0.49 \mu \mathrm{m}$ and $14.42 \pm 0.06$ $\mu \mathrm{m}$ when spray-dried at a sucrose concentration of $5 \%$ and $10 \%$ (sucrose/LNC MMR $=25$ ), respectively. The SE micrographs (Figure 3d) revealed that the microparticles were hollow, with shells containing large orifices and small crystals stuck together with small holes between the individual crystals. The particles were spherical, however deformations and formation of particle assemblies/clusters were also observed. Processing sucrose with the LNCs yielded Trojan particles that contained crystalline carbohydrate, as evidenced by a sharp melting point with an onset of $185-186^{\circ} \mathrm{C}$ in the thermograms; this peak was sharper when compared with that of sucrose spray dried without LNCs. Interestingly, another endothermic event with an onset of approximately $172-173{ }^{\circ} \mathrm{C}$ and peak at $175{ }^{\circ} \mathrm{C}$ was observed in spray dried sucrose/LNCs mixtures, which can be attributed to the presence of metastable form of sucrose [47]. PXRD confirmed the presence of crystalline carbohydrate in sucrose/LNCs mixtures (Figure 4b). The crystallisation of sucrose induced by the presence of the LNCs is probably responsible for the increased, satisfactory yield of the spray dried products.

The LNCs spray dried with sucrose were redispersible without the formation of macroscopic aggregates. The size of redispersed nanocarriers $(106 \pm 3 \mathrm{~nm}-121 \pm 1 \mathrm{~nm})$ doubled when compared with that before spray drying $(p<0.0001)$ (Figure $4 d)$. The polydispersity index $(0.172 \pm 0.018-0.241 \pm 0.030)$ was also increased after spray drying $(p<0.0001)$. Both, the size and size distribution of redispersed LNCs were significantly affected by the feed concentration $(p=0.0002$ and 0.013 for size and polydispersity index, respectively). Figure 5 a shows that sucrose/LNCs microparticles were deposited mainly in the throat and stage $1(41 \pm 2 \%$ and $30 \pm 0.5 \%$, respectively). Only a small quantity remained in the capsule and device (less than 10\%) resulting in a remarkably high total emitted dose (TED) of $91 \pm 0 \%$. Due to the small fraction of inhalable particles it was impossible to calculate the MMAD and GSD and the FPF was $15.9 \pm 1.4 \%$. Therefore, the sucrose/LNCs Trojan microparticles are not suitable for pulmonary delivery. However, they can be considered for other routes of administration such as nasal.

\subsection{Lactose-based Trojan particles}


Spray drying of either aqueous solutions of lactose or lactose/LNC mixture yielded microparticles, the size and the width of distribution of which was significantly affected by both, lactose feed concentration $(p<0.0001)$ and presence of the LNCs $(p<0.0001)$, with a significant interaction between those parameters $(p<0.0001$ ) (Figure $6 a)$. $D(0.5)$ of lactose particles varied from $2.87 \pm 0.01 \mu \mathrm{m}$ (lactose feed concentration of $0.5 \%$ ) to $6.54 \pm 0.17 \mu \mathrm{m}$ (lactose feed concentration of $10 \%$ ), whereas the $d(0.5)$ parameter of lactose-based Trojan microparticles containing LNCs at MMR $=25$ ranged between $3.71 \pm 0.06 \mu \mathrm{m}$ (lactose feed concentration of $0.5 \%$ ) and $7.85 \pm 0.24 \mu \mathrm{m}$ (lactose feed concentration of $10 \%)$. Lactose can be found in a crystalline state, an amorphous state or a mixture of both. The DSC curve (Figure 6b) of lactose starting material (alpha lactose monohydrate) showed an endothermic peak at $147.5{ }^{\circ} \mathrm{C}$, which corresponds to the loss of water of crystallisation followed by a small exothermic peak at $171.7^{\circ} \mathrm{C}$ corresponding to crystallisation of amorphous lactose and the melting endotherm with an onset at $212.8{ }^{\circ} \mathrm{C}$ corresponding to melting of anhydrous alpha [49]. PXRD diffractogram (Figure 6c) matched that of alpha lactose monohydrate, which well-defined and sharp peaks observed at $12.5,16.4,19.5$ and $20.5^{\circ} 2 \theta$ [50]. Spray dried lactose was PXRD amorphous (Figure 6c). In the DSC scan, it showed a broad endothermic event with an onset at $50.6^{\circ} \mathrm{C}$ (adsorbed moisture evaporation), an exothermic event with an onset at $176.8^{\circ} \mathrm{C}$ (crystallisation) and a melting endotherm with an onset at $208.2{ }^{\circ} \mathrm{C}$ (melting of anhydrous alpha lactose). The $\mathrm{Tg}$, which normally occurs at approximately $101{ }^{\circ} \mathrm{C}$ [51], was not observed possibly due to the interference with the broad dehydration peak. The crystallisation event and the lack of the peak at $144{ }^{\circ} \mathrm{C}$ characteristic for the monohydrate indicate the presence of amorphous lactose, supported by the PXRD results. SE micrographs of spray dried lactose display spherical particles with smooth surfaces, however the samples were hygroscopic and absorbed water very quickly resulting in fusion of the particles and the formation of a liquid-like mass (Figure 3e).

The Trojan-LNCs microparticles were spherical in shape with rough surfaces (Figure 3f). The particles were hollow, they had holes and cracks. The shell was composed of plate-like elements. Interestingly, particles spray-dried at the lowest lactose concentration of $0.5 \%$ had less spherical shape and did not form so spheres as at higher carbohydrate concentrations. The lactose/LNCs mixture spray dried at the lowest lactose feed concentration (0.5\%) showed an endothermic event with an onset at $89.4{ }^{\circ} \mathrm{C}$ (dehydration) and a sharp melting endotherm with an onset at $213.1^{\circ} \mathrm{C}$ with no visible crystallisation exotherm, thereby indicating crystallinity of this sample (Figure 6b). The samples spray dried at higher feed concentrations (1-10\%) showed broad dehydration peaks at low temperatures (onset at 31-48 ${ }^{\circ} \mathrm{C}$ ) with no visible $\mathrm{Tg}$, probably because of the interference of the dehydration peak. The broad dehydration event was followed by crystallisation (an exothermic event with an onset at approximately $146-154{ }^{\circ} \mathrm{C}$ ) and a melting endotherm with an onset at approximately $212-213{ }^{\circ} \mathrm{C}$, 
which can be attributed to melting of dehydrated alpha lactose. PXRD showed generally amorphous character of the spray dried lactose/LNCs mixtures (Figure 6c), however traces of crystalline lactose were observed at approximately $192 \theta$ degrees in samples containing lactose processed from $0.5 \%$ and $5 \%$ feeds.

The nanocarriers after spray-drying were successfully reconstituted, but their size and polydispersity index increased compared with those before spray drying $(p<0.0001)$ (Figure $6 d)$. The feed concentration had a significant effect on both, the particle diameter $(p<0.0001)$ and the polydispersity index $(p=0.007)$. When spray dried from $10 \%$ lactose, the nanocarriers doubled their size $(124 \pm 4 \mathrm{~nm})$ after spray drying. When spray dried from $0.5 \%, 1 \%$ or $5 \%$ of lactose, the size of redispersed nanocarriers was smaller, varying from $92 \pm 1$ to $100 \pm 1 \mathrm{~nm}$ for lactose feed concentration of $0.5 \%$ and $1 \%$, respectively. Both, lactose and lactose/LNCs microparticles showed a significant deposition in the capsule, throat and device with a TED of $72 \pm 2$ and $76 \pm 2 \%$, respectively (Figure $5 \mathrm{~b}$ ). The presence of LNCs significantly increased the MMAD of Trojan particles compared with lactose microparticles $(5.4 \pm 0.1 \mu \mathrm{m}$ and $4.6 \pm 0.1 \mu \mathrm{m}$, respectively). There was no difference in the FPF $(p=0.25)$, which may be attributed to a decrease in the amount of particles deposited in the device due to the presence of the LNCs.

\subsection{Trehalose-based Trojan particles}

Both, the trehalose feed concentration and the presence of LNCs exerted a significant influence on $d(0.5)$ of trehalose microparticles ( $p<0.0001$ in both cases) or Span ( $p=0.02$ and 0.002 , respectively) with a significant interaction between those parameters $(p<0.0001$ and $p=0.01$ for $s(0.5)$ and Span, respectively)) (Figure 7a). Spray drying of aqueous solution of trehalose yielded microparticles with $\mathrm{d}(0.5)$ between $3.18 \pm 0.11 \mu \mathrm{m}$ and $5.965 \pm 0.02 \mu \mathrm{m}$ for trehalose feed concentrations $0.5 \%$ and $10 \%$, respectively. The presence of LNCs (trehalose/LNC MMR=25) produced larger trehalose/LNC Trojan microparticles with $d(0.5)$ between $6.11 \pm 0.03 \mu \mathrm{m}$ and $8.34 \pm 0.00 \mu \mathrm{m}$.

In the DSC thermogram (Figure $7 \mathrm{~b}$ ) unprocessed trehalose dihydrate starting material showed an endothermic event with an onset at $94.7^{\circ} \mathrm{C}$ ascribed to loss of crystalline water and another endotherm with an onset at $210.2^{\circ} \mathrm{C}$ ascribed to melting of anhydrous trehalose, consistent with the temperatures reported previously $[25,52]$. Spray dried trehalose was amorphous as evidenced by a $\mathrm{Tg}$ with the midpoint at $123.3^{\circ} \mathrm{C}$ and the lack of either endotherm characteristic of loss of crystalline water or a melting endotherm. A broad dehydration peak was observed at lower temperatures (onset at $42.2^{\circ} \mathrm{C}$ ). PXRD data confirmed the crystalline character of the starting material and the amorphous character of spray dried trehalose (Figure 7c). Similarly to lactose, trehalose microparticles were round and showed smooth surfaces (Figure 3g). However, the spray dried powders of trehalose with the 
LNCs were mixtures of trehalose dihydrate, as evidenced by the crystalline water peak at approximately $87-92{ }^{\circ} \mathrm{C}$, and amorphous trehalose, as some samples showed a $\mathrm{Tg}$ with the midpoint at $122.1{ }^{\circ} \mathrm{C}$ (Figure 7b). A crystallisation exotherm with an onset at $150-152{ }^{\circ} \mathrm{C}$ was visible, followed by an endothermic event with an onset at $210-211{ }^{\circ} \mathrm{C}$ attributed to melting of anhydrous trehalose. In the samples with higher trehalose feed concentration ( $5 \%$ and $10 \%$ ) this peak was preceded by a small endotherm with an onset at $195-196{ }^{\circ} \mathrm{C}$. Despite the clear indication of the semi-crystalline nature of the trehalose-based Trojan particles, the powders exhibited amorphous X-ray "halos" (Figure 7c). PXRD is not sensitive enough to detect low levels of crystalline material, the detection limits for PXRD are typically on the order of a few percent crystallinity by mass [53]. SE micrographs revealed that the microparticles had small dimples and that, again, the surfaces were rough with cracks (Figure 3h).

LNCs spray dried with trehalose were successfully redispersed, although their sizes $(82 \pm 1 \mathrm{~nm}-86 \pm 1$ $\mathrm{nm}$ ) were larger than that before spray drying (Figure 7d). Both, the size and size distribution were significantly affected by spray drying $(p<0.0001)$. A substantial dose of both, trehalose and trehalose/LNCs microparticles was deposited in the capsule, device and throat (Figure 5c). The quantity of trehalose/LNCs microparticles that remained in the capsule was markedly higher than that of trehalose microparticles, resulting in a significant decrease in the TED from $73 \pm 3 \%$ to $55 \pm 5 \%$. The presence of LNCS significantly increased the MMAD from $4.0 \pm 0.3 \mu \mathrm{m}$ to $6.1 \pm 0.3 \mu \mathrm{m}(p=0.001)$. Approximately $17 \%$ of the trehalose/LNCs microparticles was deposited in stage S1 and the quantities deposited in lower stages decreased, whereas in the case of trehalose microparticles a considerable amount was deposited in S1-S4, with the highest quantity deposited in S2 (approximately $16 \%$ ). The FPF of trehalose microparticles (33.0 $\pm 3.9 \%$ ) was significantly higher than that of trehalose/LNCs Trojan microparticles $(16.7 \pm 2.8 \%)(p=0.0042)$.

\subsection{Raffinose-based Trojan particles}

The median diameter $d(0.5)$ and width of size distribution of raffinose particles depended on both, raffinose feed concentration ( $p=0.0195$ and $p=0.0001$ for $d(0.5)$ and Span, respectively) and presence of the LNCs $(p<0.0001)$, and the interaction between those parameters was significant $(p<0.0001$ and $p=0.0027$ for $d(0.5)$ and Span, respectively) (Figure $8 a)$. $D(0.5)$ of raffinose microparticles increased from $2.87 \pm 0.015 \mu \mathrm{m}$ to $6.60 \pm 0.295 \mu \mathrm{m}$ corresponding to an increase in raffinose feed concentration from $0.5 \%$ to $10 \%$. The presence of the LNCs increased the size of raffinose-LNC Trojan microparticles. When spray dried at 5 or $10 \%$ of raffinose (raffinose/LNC MMR $=25$ ), larger particles with a $d(0.5)$ parameter of approximately $8.5 \mu \mathrm{m}$ were produced, and a decrease in concentration to 0.5 or $1 \%$ resulted in the formation of smaller particles with $d(0.5)$ of approximately $5 \mu \mathrm{m}$. 
Raffinose pentahydrate starting material was crystalline, as shown by DSC (Figure 8b) and PXRD (Figure $8 \mathrm{c}$ ), and had an endothermic peak at $85.8^{\circ} \mathrm{C}$ attributed to the loss of crystalline water. Spray dried raffinose was amorphous as confirmed by DSC and PXRD. There was a Tg with the midpoint at $119.5^{\circ} \mathrm{C}$ and no dehydration endotherm. The broad endothermic event observed in DSC curve of spray dried raffinose (onset at $38.7{ }^{\circ} \mathrm{C}$ ) can be attributed to the loss of adsorbed moisture. Both, unprocessed raffinose and spray dried raffinose thermally decomposed at approximately $220^{\circ} \mathrm{C}$. Spray drying of raffinose resulted in the formation of spherical particles with smooth surfaces (Figure 9a). Raffinose/LNC Trojan microparticles (MMR $=25$ ) were amorphous, as evidenced by both, PXRD and DSC (Figure $8 \mathrm{~b}$ and $\mathrm{c}$ ). In the DSC thermograms, the broad endothermic event observed at low temperatures (onset at approximately $30^{\circ} \mathrm{C}$ ) can be attributed to the loss of moisture. The $\mathrm{Tg}$ was observed at slightly lower temperatures than that of pure amorphous raffinose. The midpoint (117.5$118.8^{\circ} \mathrm{C}$ ) increased slightly corresponding to an increasing feed concentration. Raffinose/LNCs $M M R=25$ Trojan microparticles were spherical with dimpled surfaces (Figure 9b). Spray drying had a significant influence on the diameter and polydispersity of redispersed LNCs $(p<0.0001)$ (Figure 8d). Raffinose feed concentration affected the size $(p=0.0455)$, but not the size distribution $(p=0.9177)$ of the LNCs. The nanocapsules spray dried from $1 \%$ raffinose were smaller $(88 \pm 1 \mathrm{~nm})$ than those spray dried from $0.5 \%, 5 \%$ or $10 \%$ raffinose $(94-96 \mathrm{~nm})$.

The influence of LNC loading (raffinose/LNC MMR) on the properties of raffinose-based LNC-Trojan microparticles was also examined. At the highest raffinose/LNC MMR tested (0.4) no powder was collected after spray drying in the collection vessel, and the drying chamber was covered with semisolid material, similarly to that observed in the case of LNCs spray dried without a carbohydrate. An increase in the LNC quantity (a decrease in the raffinose/LNC MMR) led to a significant $(p<0.0001)$ increase in the size of the Trojan carriers obtained and affected their distribution width (Figure 10a). The median particle diameter $\mathrm{d}(0.5)$ increased from $4.17 \pm 0.06 \mu \mathrm{m}$ to $6.54 \pm 0.40 \mu \mathrm{m}$ after decreasing the raffinose/LNCs MMR from 100 to 1.6. A further decrease in the MMR to 0.8 led to a drastic increase in $\mathrm{d}(0.5)$ to $11.66 \pm 1.54 \mu \mathrm{m}$. DSC scans (Figure 10b) and X-ray diffractograms (Figure 10c) show that all spray dried raffinose/LNCs mixtures were amorphous. At the highest LNC concentration (raffinose/LNC MMR=0.8) a small endothermic event with an onset at $28^{\circ} \mathrm{C}$ was observed in the DSC scan corresponding to melting of MHS. Broad endothermic peaks with an onset at approximately 34$40{ }^{\circ} \mathrm{C}$ that were observed in all DSC thermograms can be attributed to moisture loss. The LNC loading affected the $\mathrm{Tg}$ of samples and its position moved gradually towards lower temperatures corresponding to an increase in the LNC loading. The midpoint shifted from $119.2^{\circ} \mathrm{C}$ to $112.9^{\circ} \mathrm{C}$ for the raffinose/LNC MMR 100 to 0.8 , respectively. Thermal decomposition was observed at $210-220^{\circ} \mathrm{C}$. The morphology and shape of raffinose/LNC Trojan particles was affected by the LNC loading (Figure 
9c and d). LNCs spray dried with raffinose at $1 \%$ at $M M R=100$ yielded spherical isolated particles with dimpled outer surfaces, however when spray dried from a $1 \%$ raffinose at high LNC concentration (raffinose/LNC MMR=1.6) the particle surfaces had some visible holes and the shape was not spherical.

LNCs spray dried with raffinose were successfully reconstituted, with the particle size of the redispersed nanocarriers smaller than $100 \mathrm{~nm}$, with the exception of LNCs spray dried from $1 \%$ raffinose at MMR=100 $(109 \pm 1 \mathrm{~nm})$ (Figure 10d). Both, the size and size distribution were dependent on the LNC loading $(p<0.0001)$. Interestingly, the LNCs spray dried from $1 \%$ raffinose at MMR=100 (109 $\mathrm{nm})$ were markedly larger than those spray dried at MMRs 1.6-50 (86-93 nm). Also, the LNCs spray dried at the highest $\mathrm{MMR}=0.8$ were the smallest reconstituted nanocapsules with diameters of $78 \pm 1 \mathrm{~nm}$.

Raffinose microparticles with no LNC showed an MMAD of $4.1 \pm 0.1 \mu \mathrm{m}$ (Figure $5 \mathrm{~d}$ ). Incorporation of LNCs exerted a significant effect $(p<0.0001)$ on the MMAD increasing it to $5.3 \pm 0.1 \mu \mathrm{m}$ and to $6.2 \pm 0.1$ $\mu \mathrm{m}$ for raffinose/LNC MMRs of 25 and 1.6, respectively. However, the LNCs did not affect the GSD of raffinose-based microparticles $(p=0.2963)$. The presence of LNCs significantly affected the TED $(p=0.0017)$. The TED of raffinose microparticles was $73 \pm 2 \%$. It increased to $64 \pm 1 \%$ after incorporation of the LNCS (MMR=25), but a further increase in the quantity of LNCs (MMR=1.6) led to an increase in the TED to $75 \pm 3 \%$. The latter raffinose/LNC Trojan microparticles were deposited mainly in the device, throat and stages 1 and 2 . The presence of LNCs significantly influenced the FPF ( $p<0.0001$ ), leading to a decrease in the FPF corresponding to an increase in the LNC quantity. Nonetheless, the worse aerodynamic performance (i.e. higher MMAD and FPF) of raffinose/LNC MMR=1.6 particles may be compensated by an increased LNC loading (the LNC concentration was 16 times higher than in the raffinose/LNC MMR=25 particles) and higher TED, thereby increasing the quantity of the LNCs that could reach the deep lungs. However, larger quantities of LNCs would also be deposited in the throat and upper respiratory tract in the case of raffinose/LNC MMR=1.6 particles. Hence, a compromise must be made between the aerodynamic performance of Trojan particles and the dose of LNCs delivered to deep lungs, so both factors need to be considered in optimisation of the LNC-Trojan microparticle formulation.

\section{General discussion}

Aerodynamic performance is a very important factor for inhaled formulations because it is correlated with lung deposition [29]. There are three principal mechanisms leading to deposition of inhaled materials in the lungs: inertial impaction, gravitational sedimentation and Brownian diffusion [2]. A successful deposition into deep lung requires that the inhaled particles are small enough to pass through the lower airways avoiding deposition by inertial impaction in the upper airways, but large 
enough to avoid exhalation [2]. Particles with the MMAD that ranges from 1 to $5 \mu \mathrm{m}$ are likely to be subjected to sedimentation by gravitational force in smaller airways and respiratory [2]. Neither mannitol-LNC nor sucrose-LNC Trojan particles can be considered for pulmonary application. The presence of the LNCS considerably increased both, the median particle diameter and MMAD. Trehalose-LNC Trojan particles were characterised by a considerably higher MMAD $(6.1 \pm 0.3 \mu \mathrm{m})$ that either lactose-LNC $(5.4 \pm 0.1 \mu \mathrm{m})$ or raffinose-LNC $(5.3 \pm 0.1 \mu \mathrm{m})$ Trojan microparticles. High average GSD values (2.3-3.0 $\mu \mathrm{m})$ suggest variations in aerodynamic diameter. The FPF and TED decreased in the following order: lactose-LNC>raffinose-LNC>trehalose-LNC Trojan particles. An important quantity of the microparticles either remained in the capsule or was deposited in the device. Such phenomenon is typically caused by van der Waals, capillary and electrostatic forces [29]. Interestingly, the quantity of particles in the capsule and throat was considerably low for sucrose-LNC Trojan microparticles (less than $10 \%)$. Hence, carbohydrate blends could be considered as a suitable material for the fabrication of LNC-Trojan particles. The spray dried particles were non-porous with the aerodynamic diameters very close to geometric diameters. The differences between the MMAD and median particle diameter $d(0.5)$ were relatively small for carbohydrate/LNCs microparticles $(0.2-0.3 \mu \mathrm{m})$, whereas in the case of some carbohydrates without the LNCs (raffinose and lactose) these differences were larger (0.8 and $1.2 \mu \mathrm{m}$, respectively). Hence, determination of geometric diameter should prove useful for formulation screening of LNC-Trojan particles.

An increase in the microparticle size of Trojan particles containing LNCs compared with blank carbohydrate microparticles may be attributed to changes in solid state properties induced by the LNCs. LNCs induced crystallisation of sucrose and increased the yield of the particles. Similarly, when spray dried in the presence of LNCS, the lactose-LNC and trehalose-LNCs systems were not fully amorphous (Figures 6 and 7), in contrast with blank carbohydrate microparticles. The increased crystallinity of carbohydrates containing LNCs may be attributed to the fact that MHS is an ether of PEG, and it also contains approximately $30 \%$ of free PEG. Crystallisation of carbohydrates in the presence of PEG molecules has previously been reported. Chidavaenzi et al., [54] found that lactose when spray dried on its own was amorphous, but spray drying in the presence of PEG4000 yielded products that were crystalline and contained lactose crystals. It has been postulated that the solidification rates of lactose in the presence of PEG were slower than those of lactose alone [54]. It is likely that lactose crystallises in the presence of PEG because of the high affinity with which PEG hydrogen bonds water, which can slow the drying process [54]. Similarly, the presence of PEG2000 in a spray drying feed caused crystallisation of trehalose to form trehalose dihydrate [25]. It has been suggested that PEGs and trehalose do not molecularly mix because there was no change in the $\mathrm{Tg}$ of trehalose in the presence of PEG2000 [25]. In the current study, the Tg of trehalose was not markedly 
modified in the presence of LNCs. Interestingly, the LNCs did not induce crystallisation of raffinose and they depressed the Tg of raffinose, hence the LNCs mix easier, at the molecular level, with raffinose than with trehalose.

Inadequate reconstitution of the nanocarriers in aqueous media represents a major obstacle in any drying process because it may lead to the formation of large particle aggregates and the loss of beneficial colloidal properties of the nanosystem. The encapsulation within Trojan particles requires that once entrapped in the dried microparticles the nanocarriers should conserve their size and individual nature. This can be examined by redispersion of the dried powder in water [34]. The powders were instantaneously dissolved in water and the LNCs were successfully reconstituted from all tested carbohydrate/LNC Trojan microparticles. Generally the sucrose-LNC and lactose-LNC spray dried from $10 \%$ lactose yielded the largest nanocarriers with the sizes of 106-124 nm. Mannitol-LNC produced the nanocapsules with the sizes above $100 \mathrm{~nm}$ as well. Lactose (0.5-5\%), raffinose and trehalose generally yielded the nanocapsules with the sizes below $100 \mathrm{~nm}$. Trehalose seemed to be the most effective carbohydrate to achieve the preservation of the nanocapsule properties, with the LNCs between 82-86 $\mathrm{nm}$. Trehalose is synthesized by certain living organisms such as plants, seeds, invertebrates under low humidity conditions and permits these organisms to be dried at high temperatures and confers their cells the ability to survive under extreme conditions of dehydration. The solutions of trehalose and other carbohydrates are known to easily form glasses. It has been suggested that trehalose, which has a high $\mathrm{Tg}$, controls the mobility of water during the glassy state formation [55]. The role of the disaccharides in stabilisation of lipidic nanocarriers is to form a vitrified matrix around the lipids and to replace the water in dry state around the hydrophilic head groups [11]. The increase in size has been observed by other authors for other NPs incorporated within Trojan particles. For instance, microemulsions showed a significant increase in the size after spray drying, and the size was generally doubled compared with that before spray drying. This was attributed to slight droplet coalescence due to turbulence and heat during the spray drying process [34]. Thermal stress during droplet drying, high shear stress in the nozzle seem to be factors responsible for the increased size of the LNCs after spray drying. This kind of stress should be more pronounced at higher LNC concentrations. Interestingly, the smallest LNCs, with a diameter of $78 \pm 1 \mathrm{~nm}$ were obtained after spray drying of raffinose/LNC system with the highest LNC loading. It has been demonstrated that the LNCs behave like surfactant molecules in the sense that they adsorb at the air/water interface and decrease surface tension [18]. It is believed that at the air/water interface some of the MHS molecules are released from the LNC structure. Consequently, the LNCs located at the surface may have their structure reorganized, fuse and aggregate $[18,19]$. It has been demonstrated that during nebulization the LNCs increase their size, and this phenomenon is more pronounced at lower LNC concentration 
[19]. Similarly to the nebulization process, during spray drying the bulk liquid is transformed into an aerosol, which has a far greater air/water interface area compared with bulk liquid. Hence, the phenomenon of LNC adsorption on the surface becomes more important. The effect of surface adsorption on the increase in LNC size is more pronounced at lower LNC concentrations, because the relative percentage of LNCs which are adsorbed and have their structure reorganised is higher. Hence, LNCs adsorption on greatly expanded liquid/air interface of the sprayed solution may be responsible for the aggregation of the LNCs as well. However, during the spray drying process the exposure of LNCs to temperature may be more pronounced than during nebulization. Also, as a result of water evaporation, the LNC concentration rapidly increases. The LNCS are obtained by the phase inversion temperature method, however the outlet temperature $\left(66^{\circ} \mathrm{C}\right)$ is below the phase inversion temperature of tested formulation $\left(82^{\circ} \mathrm{C}\right)$, so the aqueous phase should remain the continuous phase of the system. Nonetheless, the phase inversion process can be affected by various molecules, hence it cannot be excluded that the carbohydrates affect the phase inversion process, thereby affecting the properties of the obtained product.

The data obtained indicate that raffinose is the preferred choice for spray drying of LNCs. It shows satisfactory preservation of the colloidal properties, such as size of the incorporated nanocarriers, similarly to trehalose or lactose. The disadvantage of lactose is that, due to its carbohydrateassociated reducing function, it may interact with functional groups of drugs or peptides and proteins [3]. Another disadvantage of either lactose or trehalose microparticles are changes in solid state properties such as induction of crystallisation by the presence of the LNCs. Raffinose/LNC particles show better aerodynamic properties (lower MMAD) than trehalose/LNC microparticles.

\section{Conclusions}

In this study we successfully produced spray dried carbohydrate-based microparticles containing LNCS called LNC-Trojan microparticles. Generally, the presence of LNCs had a significant impact on the size and morphology of the spray dried particles. Introduction of the LNCs also changed the solid state properties of the processed carbohydrates. However, the spray drying process did not destroy the LNCs, which can be easily redispersed after adding water to the powders with satisfactory preservation of their properties such as size. Our data indicate that raffinose is the preferred choice in order to maintain good LNC redispersibility, satisfactory aerodynamic properties of Trojan particles and reasonable solid state properties (amorphous carbohydrate). They appear to be robust delivery systems that may be useful for pulmonary delivery of a wide variety of drugs, thereby combining the advantages of LNCS with delivery conveniences of the carbohydrate Trojan particles. However, further studies are necessary that require the incorporation of a drug and exploration of the use of other 
additives together with raffinose, either a carbohydrate blend or an excipient with surface active properties to displace LNCs from the Trojan particle surface.

\section{Acknowledgments}

The authors acknowledge funding from the Ireland-France Ulysses research funding programme (Campus France and Irish Research Council). This study received funding from the Synthesis and Solid State Pharmaceutical Centre (SSPC), financed by a research grant from Science Foundation Ireland (SFI) and co-funded under the European Regional Development Fund (Grant Number 12/RC/2275). The research leading to these results also received funding from the European Union's Seventh Framework Program (FP7/2007-2013) under grant agreement no 604182 (http://ec.europa.eu.research). It was carried out within the project FORMAMP-Innovative Nanoformulation of Antimicrobial Peptides to Treat Bacterial Infectious Diseases.

\section{References}

[1] J.O. Sham, Y. Zhang, W.H. Finlay, W.H. Roa, L. Lobenberg, Formulation and characterization of spray-dried powders containing nanoparticles for aerosol delivery to the lung. Int. J. Pharm. 269 (2004) 457-467. https://doi.org/10.1016/j.ijpharm.2003.09.041

[2] W. Yang, J.I. Peters, R.O. Williams III, Inhaled nanoparticles- A current review. Int. J. Pharm. 356 (2008) 239-247. https://doi.org/10.1016/j.ijpharm.2008.02.011

[3] G. Pilcer, K. Amighi, Formulation strategy and use of excipients in pulmonary drug delivery. Int. J. Pharm. 392 (2010) 1-19. https://doi.org/10.1016/j.ijpharm.2010.03.017

[4] O. Ni Ogain, L. Li, L. Tajber, O.I. Corrigan, A.M. Healy, Particle engineering of materials for oral inhalation by dry powder inhalers. I-Particles of sugar excipients (trehalose and raffinose) for protein delivery. Int. J. Pharm. 405 (2011) 23-35. https://doi.org/10.1016/j.ijpharm.2010.11.039

[5] O. Ni Ogain, L. Tajber, O.I. Corrigan, A.M. Healy, Spray drying from organic solvents to prepare nanoporous/nanoparticulate microparticles of protein: excipient composites designed for oral inhalation. J. Pharm. Pharmacol. 64 (2012) 1275-1290. https://doi.org/10.1111/j.20427158.2012.01488.x

[6] D.S. Anderson, M.J. Sydor, P. Fletcher, A. Holian, Nanotechnology: The Risks and Benefits for Madical Diagnosis and Treatment. J. Nanomed. Nanotechnol. 7 (2016) e143 doi:10.4172/2157$7439.1000 \mathrm{e} 143$

[7] A. Umerska, K.J. Paluch, M.J. Santos-Martinez, C. Medina, O.I. Corrigan, L. Tajber, Chondroitinbased nanoplexes as peptide delivery systems - Investigations into the self-assembly process, solidstate and extended release characteristics. Eur. J. Pharm. Biopharm. 93 (2015) 242-253. https://doi.org/10.1016/j.ejpb.2015.04.006 
[8] A. Umerska, O.I. Corrigan, L. Tajber, Design of chondroitin sulfate-based polyelectrolyte nanoplexes: Formation of nanocarriers with chitosan and a case study of salmon calcitonin. Carbohydr. Polym. 156 (2017) 276-284. https://doi.org/10.1016/j.carbpol.2016.09.035

[9] A.-C. Groo, N. Matougui, A. Umerska, P. Saulnier, Reverse micelle-lipid nanocapsules: a novel strategy for drug delivery of the plectasin derivate AP138 antimicrobial peptide. Int. J. Nanomedicine 13 (2018) 7565-7574. https://doi.org/10.2147/IJN.S180040

[10] H. Nehme, P. Saulnier, A.A. Ramadan, V. Cassisa, C. Guillet, M. Eveillard, A. Umerska, Antibacterial activity of antipsychotic agents, their association with lipid nanocapsules and its impact on the properties of the nanocarriers and on antibacterial activity. PLOS ONE 13 (2018) e0189950. https://doi.org/10.1371/journal.pone.0189950

[11] L. Boge, A. Vastberg, A. Umerska, H. Bysell, J. Eriksson, K. Edwards, A. Millqvist-Fureby, M. Andersson, Freeze-dried and re-hydrated liquid crystalline nanoparticles stabilized with disaccharides for drug-delivery of the plectasin derivative AP114 antimicrobial peptide. J. Coll. Interf. Sci. 522 (2018) 126-135. https://doi.org/10.1016/j.jcis.2018.03.062

[12] A. Kumari, R. Singla, A. Guliani, S.K. Yadav, Nanoencapsulation for drug delivery. EXCLI Journal, 13 (2014) 265-286. PMCID: PMC4464443

[13] A. Puri, K. Loomis, B. Smith, J.H. Lee, A. Yavlovich, E. Heldman, R. Blumenthal, Lipid-based nanoparticles as pharmaceutical drug carriers: from concepts to clinic. Crit. Rev. Ther. Drug Carrier Syst. 26 (2009) 523-580. PMCID: PMC2885142

[14] N.T. Huynh, C. Passirani, P. Saulnier, J.P. Benoit, Lipid nanocapsules: a new platform for nanomedicine. Int. J. Pharm. 379 (2009) 201-209. https://doi.org/10.1016/j.ijpharm.2009.04.026

[15] J. Hureaux, F. Lagarce, F. Gagnadoux, L. Vecellio, A. Claverul, E. Roger, M. Kempf, J.L. Racineux, P. Diot, J.P. Benoit, T. Urban, Lipid nanocapsules: ready-to-use nanovectors for the aerosol delivery of paclitaxel. Eur. J. Pharm. Biopharm. 73 (2009) 239-246. https://doi.org/10.1016/j.ejpb.2009.06.013

[16] J. Hureaux, F. Lacoeuille, F. Lagarce, M.C. Rousselet, A. Contini, P. Saulnier, J.P. Benoit, T. Urban, Absence of lung fibrosis after a single pulmonary delivery of lipid nanocapsules in rats. Int. J. Nanomedicine 12 (2017) 8159-8170. doi: 10.2147/IJN.S146740

[17] A. Umerska, V. Cassisa, G. Bastiat, N. Matougui, H. Nehme, F. Manero, M. Eveillard, P. Saulnier, Synergistic interactions between antimicrobial peptides derived from plectasin and lipid nanocapsules containing monolaurin as a cosurfactant against Staphylococcus aureus. Int. J. Nanomedicine 12 (2017) 5687-5699. doi: 10.2147/IJN.S139625

[18] C.R.A. Mouzouvi, A. Umerska, A.K. Bigot, P. Saulnier, Surface active properties of lipid nanocapsules. PLOS ONE 12 (2017) e0179211. https://doi.org/10.1371/journal.pone.0179211

[19] A. Umerska, C.R. A., Mouzouvi, A. Bigot, P. Saulnier, Formulation and nebulization of fluticasone propionate-loaded lipid nanocarriers. Int. J. Pharm. 493 (2015) 224-232. https://doi.org/10.1016/j.ijpharm.2015.07.008 
[20] A. Umerska, N. Matougui, A.-C. Groo, P. Saulnier, Understanding the adsorption of salmon calcitonin, antimicrobial peptide AP114 and polymyxin B onto lipid nanocapsules. Int. J. Pharm. 506 (2016) 191-200. https://doi.org/10.1016/j.ijpharm.2016.04.028

[21] M.M. Bailey, C.J. Berkland, Nanoparticle Formulations in Pulmonary Drug Delivery. Med. Res. Rev. 29 (2009) 196-212. https://doi.org/10.1002/med.20140.

[22] A. Paclawski, J. Szlek, R. Lau, R. Jachowicz, A. Mendyk, Empirical modeling of the fine particle fraction for carrier-based pulmonary delivery formulations. Int. J. Nanomedicine 10 (2015) 801-810. https://doi.org/10.2147/IJN.S75758

[23] S.R.B. Behara, P.W. Longest, D.R. Farkas, M. Hindle, Development and Comparison of New High Efficiency Dry Powder Inhalers for Carrier-Free Formulations. J. Pharm. Sci. 103 (2014) 465-477. https://doi.org/10.1002/jps.23775

[24] N. Tsapis, D. Bennett, B. Jackson, D. Weitz, D. Edwards, Trojan particles: large porous carriers of nanoparticles for drug delivery. Proc. Nat. Acad. Sci. USA 99 (2002) 12001-12005. https://doi.org/10.1073/pnas.182233999

[25] A. Umerska, K.J. Paluch, M.J. Santos-Martinez, O.I. Corrigan, C. Medina, L. Tajber, Freeze drying of polyelectrolyte complex nanoparticles: Effect of nanoparticle composition and cryoprotectant selection. Int. J. Pharm. 552 (2018) 27-38. https://doi.org/10.1016/j.ijpharm.2018.09.035

[26] S. Azarmi, W.H. Roa, R. Lobenberg, Targeted delivery of nanoparticles for the treatment of lung diseases. Adv. Drug Deliv. Rev. 60 (2008) 863-875. https://doi.org/10.1016/j.addr.2007.11.006

[27] D. Xia, N. Shrestha, J. van de Streek, H. Mu, M. Yang, Spray drying of fenofibrate loaded nanostructured lipid carriers. Asian J. Pharm. Sci. 11 (2016) 507-515. https://doi.org/10.1016/j.ajps.2016.01.001

[28] E. Assadpour, S.M. Jafari, Advances in Spray-Drying Encapsulation of Food Bioactive Ingredients: From Microcapsules to Nanocapsules. Annu. Rev. Food Sci. Technol. 10 (2019) 103-131. https://doi.org/10.1146/annurev-food-032818-121641

[29] S. Liu, A.B. Watts, J. Du, A. Bui, S. Hengsawas, J.I. Peters, R.O. Willimas III, Formulation of a novel fixed dose combination of salmeterol xinafoate and mometasone furoate for inhaled drug delivery. Eur. J. Pharm. Biopharm. 96 (2015) 132-142. https://doi.org/10.1016/j.ejpb.2015.07.017

[30] M.I. Amaro, L. Tajber, O.I. Corrigan, A.M. Healy, Optimisation of spray drying process conditions for sugar nanoporous microparticles (NPMPs) intended for inhalation. Int. J. Pharm. 421 (2011) 99109. https://doi.org/10.1016/j.ijpharm.2011.09.021

[31] P. Maher, Y.H. Roos, M.A. Fenelon, Physicochemical properties of spray dried nanoemulsions with varying final water and sugar contents. J. Food Eng. 126 (2014) 113-119. https://doi.org/10.1016/j.jfoodeng.2013.11.001

[32] C. Gomez-Gaete, E. Fattal, L. Silva, M. Besnard, N. Tsapis, Trojan particles: large porous carriers of nanoparticles for drug delivery. J. Control. Release 128 (2008) 41-49. https://doi.org/10.1073/pnas.182233999 
[33] T. Lebhardta, S. Roeslera, H.P. Uusitalo, T. Kissel, Surfactant-free redispersible nanoparticles in fast-dissolving composite microcarriers for dry powder inhalation. Eur. J. Pharm. Biopharm. 78 (2011) 90-96. https://doi.org/10.1016/j.ejpb.2010.12.002

[34] X. Li, N. Anton, T.M.C. Ta, M. Zhao, N. Messadeq, T.F. Vandamme, Microencapsulation of nanoemulsions: novel Trojan particles for bioactive lipid molecule delivery. Int. J. Nanomed. 6 (2011) 1313-1325. https://doi.org/10.2147/IJN.S20353

[35] M.E. Ali, A. Lamprecht, Spray freeze drying for dry powder inhalation of nanoparticles. Eur. J. Pharm. Biopharm. 87 (2014) 510-517. https://doi.org/10.1016/j.ejpb.2014.03.009

[36] K.P.M. McComiskey, A. McDonagh, L. Tajber, Isolation of Itraconazole Nanostructured Microparticles via Spray Drying with Rational Selection of Optimum Base for Successful Reconstitution and Compaction. AAPS PharmSciTech 20 (2019) 217. https://doi.org/10.1208/s12249-019-1436-6

[37] S.M. Jafari, E. Assadpoor, B. Bhandari, Y. He, Nano-particle encapsulation of fish oil by spray drying. Food Res. Int. 41 (2008) 172-183. http://dx.doi.org/10.1016/j.foodres.2007.11.002

[38] K. Sarabandi, S.M. Jafari, M. Mohammadi, Z. Akbarbaglu, A. Pezeshki, M. Khakbaz-Heshmati, Production of reconstitutable nanoliposomes loaded with flaxseed protein hydrolysates: Stability and characterization. Food Hydrocoll. 96 (2019) 442-450. https://doi.org/10.1016/j.foodhyd.2019.05.047

[39] S.M. Jafari, Y. He, B. Bhandari, Encapsulation of Nanoparticles of d-Limonene by Spray Drying: Role of Emulsifiers and Emulsifying Techniques. Dry. Technol. 25 (2007) 1069-1079. https://doi.org/10.1080/07373930701396758

[40] N.A. Mugheirbi, K.J. Paluch, L. Tajber, Heat induced evaporative antisolvent nanoprecipitation (HIEAN) of itraconazole. Int. J. Pharm. 471 (2014) 400-411. https://doi.org/10.1016/j.ijpharm.2014.05.045

[41] F. Tewes, K.J. Paluch, L. Tajber, K. Gulati, D. Kalantri, C. Ehrhardt, A.M. Healy, Steroid/mucokinetic hybrid nanoporous microparticles for pulmonary drug delivery. Eur J Pharm Biopharm 85 (2013) 604613. https://doi.org/10.1016/j.ejpb.2013.03.020

[42] L. Tajber, O.I. Corrigan, A.M. Healy, Spray drying of budesonide, formoterol fumarate and their composites-II. Statistical factorial design and in vitro deposition properties. Int. J. Pharm. 367 (2009) 86-96. https://doi.org/10.1016/j.ijpharm.2008.09.029

[43] B. Heurtault, P. Saulnier, B. Pech, J.E. Proust, J.P. Benoit, A novel phase-inversion based process for the preparation of lipid nanocarriers. Pharm. Res. 19 (2002) 875-880. https://doi.org/10.1023/A:1016121319668

[44] S.G. Maas, G. Schaldach, E.M. Littringer, A. Mescher, U.J. Griesser, D.E. Braun, P.E. Walzel, N.A. Urbanetz, The impact of spray drying outlet temperature on the particle morphology of mannitol. Powder Technol. 213 (2011) 27-35. https://doi.org/10.1016/j.powtec.2011.06.024

[45] A. Burger, J.O. Henck, S. Hetz, J.M. Rollinger, A.A. Weissnicht, H. Stottner, Energy/temperature diagram and compression behavior of the polymorphs of D-mannitol. J. Pharm. Sci. 89 (2000) 457-468. https://doi.org/10.1002/(SICI)1520-6017(200004)89:4\%3C457::AID-JPS3\%3E3.0.CO;2-G 
[46] M.G. Cares-Pacheco, G. Vaca-Medina, R. Calvet, F. Espitalier, J.J. Letourneau, A. Rouilly, E. Rodier, Physicochemical characterization of D-mannitol polymorphs: The challenging surface energy determination by inverse gas chromatography in the infinite dilution region. Int. J. Pharm. 475 (2014) 69-81. https://doi.org/10.1016/j.ijpharm.2014.08.029

[47] T. Lee, G.D. Chang, Sucrose Conformational Polymorphism: A Jigsaw Puzzle with Multiple Routes to a Unique Solution. Crystal Growth \& Design 9 (2009) 3551-3561. https://doi.org/10.1021/cg900294d

[48] A. Simperler, A. Kornherr, R. Chopra, P.A. Bonnet, W. Jones, W.D.S. Motherwell, G. Zifferer, Glass Transition Temperature of Glucose, Sucrose, and Trehalose: An Experimental and in Silico Study. J. Phys. Chem. B 110 (2006) 19678-84. https://doi.org/10.1021/jp063134t

[49] W. Kaialy, G.P. Martin, M.D. Ticehurst, P. Royall, M.A. Mohammad, J. Murphy, A. Nokhodchi, Characterisation and Deposition Studies of Recrystallised Lactose from Binary Mixtures of Ethanol/Butanol for Improved Drug Delivery from Dry Powder Inhalers. AAPS J. 13 (2010) 30-43. https://doi.org/10.1208/s12248-010-9241-x

[50] A.L. Lopez-Pablos, C.C. Leyva-Porras, M.B. Silva-Cazares, F.E. Longoria-Rodriguez, S.A. PerezGarcia, A.A. Vertiz-Hernandez, M.Z. Saavedra-Leos, Preparation and Characterization of High Purity Anhydrous $\beta$-Lactose from $\alpha$-Lactose Monohydrate at Mild Temperature. Int. J. Polym. Sci. vol 2018 (2018) Article ID 5069063. https://doi.org/10.1155/2018/5069063

[51] Y.H. Roos, Importance of glass transition and water activity to spray drying and stability of dairy powders. Lait 82 (2002) 475-484. https://doi.org/10.1051/lait:2002025

[52] S. Ohtake, Y.I. Wang, Trehalose: current use and future applications. J. Pharm. Sci. 100 (2011) 2020-2053. https://doi.org/10.1002/jps.22458

[53] J.A. Newman, P.D. Schmitt, J.T. Scott, F. Deng, S. Zhang, G.I. Simpson, Parts per Million Powder Xray Diffraction. Anal. Chem. 87 (2015) 10950-10955. https://doi.org/10.1021/acs.analchem.5b02758

[54] O.C. Chidavaenzi, G. Buckton, F. Koosha, The effect of co-spray drying with polyethylene glycol 4000 on the crystallinity and physical form of lactose. Int. J. Pharm. 216 (2001) 43-49. https://doi.org/10.1016/S0378-5173(00)00693-1

[55] F. Sussich, R. Urbani, F. Princivalle, A. Cesaro, Polymorphic Amorphous and Crystalline Forms of Trehalose. J Am Chem Soc 120 (1998) 7893-7899. https://doi.org/10.1021/ja9800479 


\section{Figure captions}

Figure 1 Differential scanning thermogram (a) and powder X-ray diffractogram (b) of dry LNCs.

Figure 2 Properties of mannitol microparticles and mannitol-based LNC-Trojan particles. (a) median particle diameter (bars) and Span (filled squares), (b) DSC thermograms, (c) powder X-ray diffractograms, (d) hydrodynamic diameter (bars) and polydispersity index (filled squares) of LNCs reconstituted from spray dried mannitol/LNC Trojan particles with carbohydrate/LNC mass mixing ratio $M M R=25$. Results in (a) and (d) are expressed as mean values $(n=3) \pm$ standard deviation and compared using two-way ANOVA.

Figure 3 SE micrographs of (a) mannitol particles spray dried from $1 \%$ solution (b) mannitol-based particles (mannitol/LNC MMR=25, mannitol concentration: 1\%), (c) sucrose spray dried from 5\% solution (d) sucrose-based particles (sucrose/LNC MMR=25, sucrose concentration: $5 \%$ ), (e) lactose particles spray dried from $1 \%$ solution (f) lactose-based particles (lactose/LNC MMR=25, lactose concentration: $5 \%),(\mathrm{g})$ trehalose particles spray dried from $1 \%$ solution $(\mathrm{h})$ trehalose-based particles (trehalose/LNC MMR=25, trehalose concentration: 1\%).

Figure 4 Properties of sucrose microparticles and sucrose-based LNC-Trojan particles. (a) DSC thermograms, (b) powder X-ray diffractograms, (c) median particle diameter (bars) and Span (filled squares), (d) hydrodynamic diameter (bars) and polydispersity index (filled squares) of LNCs reconstituted from spray dried sucrose-based LNC-Trojan particles with carbohydrate/LNC mass mixing ratio $M M R=25$. Results in (c) and (d) are expressed as mean values $(n=3) \pm$ standard deviation and compared using two-way ANOVA.

Figure 5 In vitro aerosol deposition profile of (a) sucrose/LNC Trojan particles, (b) lactose/LNC Trojan particles, (c) trehalose/LNC Trojan particles and (d) raffinose/LNC Trojan particles by using a next generation impactor (NGI). MMAD: mass median aerodynamic diameter, GSD: geometric standard deviation, TED: total emitted dose, FPF: fine particle fraction, MMR: mass mixing ratio, CFC: carbohydrate feed concentration.

Figure 6 Properties of lactose microparticles and lactose-based LNC-Trojan particles. (a) median particle diameter (bars) and Span (filled squares), (b) DSC thermograms, (c) powder X-ray diffractograms, (d) hydrodynamic diameter (bars) and polydispersity index (filled squares) of LNCs reconstituted from spray dried lactose-based LNC-Trojan particles with carbohydrate/LNC mass mixing ratio $M M R=25$. Results in (a) and (d) are expressed as mean values $(n=3) \pm$ standard deviation and compared using two-way ANOVA. 
Figure 7 Properties of trehalose microparticles and trehalose-based LNC-Trojan particles. (a) median particle diameter (bars) and Span (filled squares), (b) DSC thermograms, (c) powder X-ray diffractograms, (d) hydrodynamic diameter (bars) and polydispersity index (filled squares) of LNCs reconstituted from spray dried trehalose-based LNC-Trojan particles with carbohydrate/LNC mass mixing ratio $M M R=25$. Results in (a) and (d) are expressed as mean values $(n=3) \pm$ standard deviation and compared using two-way ANOVA. The median particle and LNC diameters are presented as bars, while Span and polydispersity index are shown as filled squares.

Figure 8 Properties of raffinose microparticles and raffinose-based LNC-Trojan particles. (a) median particle diameter (bars) and Span (filled squares), (b) DSC thermograms, (c) powder X-ray diffractograms, (d) hydrodynamic diameter (bars) and polydispersity index (filled squares) of LNCS reconstituted from spray dried raffinose-based LNC-Trojan particles with carbohydrate/LNC mass mixing ratio $M M R=25$. Results in (a) and (d) are expressed as mean values $(n=3) \pm$ standard deviation and compared using two-way ANOVA.

Figure 9 SE micrographs of (a) raffinose particles spray dried from $1 \%$ solution, (b), (c) and (d) raffinosebased particles (raffinose concentration: 1\%, raffinose/LNC MMRs of 25, 100 and 1.6, respectively).

Figure 10 Properties of raffinose microparticles and raffinose-based LNC-Trojan particles as a function of LNC loading. (a) median particle diameter (bars) and Span (filled squares), (b) DSC thermograms, (c) powder X-ray diffractograms, (d) hydrodynamic diameter (bars) and polydispersity index (filled squares) of LNCs reconstituted from spray dried raffinose-based LNC-Trojan particles with varying raffinose/LNC mass mixing ratio MMR. Results in (a) and (d) are expressed as mean values $(n=3) \pm$ standard deviation and compared using one-way ANOVA. 